\title{
e-interview
}

\section{Ahmed Okasha}

Ahmed Okasha is Professor of Psychiatry, Ain Shams University, Cairo and Director, WHO Collaborating Centre for Training and Research in Mental Health, Institute of Psychiatry, Cairo. He trained at the Ain Shams University Hospitals, Cairo and the Institute of Psychiatry, London. His special interests include transcultural clinical studies, ethnic pharmaco-psychiatry and psychiatry from the Pharoanic to Greco-Islamic Arabic era.

If you were not a psychiatrist, what would you do?

A conductor of a philharmonic orchestra. I do not play any musical instrument but I can appreciate music and it stimulates both my creativity and spirituality.

What has been the greatest impact of your profession on you personally? To establish warm interpersonal relationships, to enjoy a family and social network, and to accept and perceive others in a merciful way. I do believe that longevity of life at the expense of quality of life is an empty prize.

\section{What are your interests outside of} work?

Reading, listening to music and walking daily in the sporting club.

Who was your most influential trainer, and why?

When I arrived in London at the Institute of Psychiatry, Maudsley Hospital, I asked Sir Aubrey Lewis what textbook I should read; he advised The Castle and TheTrial by Kafka. I was hurt when I realised that they were paperback books. I went in anger and informed him that I was here on a mission and not to read stories. He smiled and asked me to read them and come back. Later on he told me that the best way to study psychiatry is to see the pattern of thoughts and behaviour in novels, plays, mythology and art not only in patients.

What job gave you the most useful training experience?

Working with R.F. Hobson at the Institute of Psychiatry in the psychotherapy unit. The work was based on Jungian analytical psychology where culture, philosophy, humanity and mental health intermingle.

Which book has influenced you most? Clinical Psychiatry (Mayer-Gross), General Psychopathology (Jaspers), Fighting for Mental Health: A Personal View (Sartorius), Ebers and Kahoun Papyri where mental disorders were mentioned as heart and uterine disorders 5000 years ago.

What research publication has had the greatest influence on your work? The National Institute for Mental Health epidemiological survey: The Global Burden of Disease: A Comprehensive Assessment

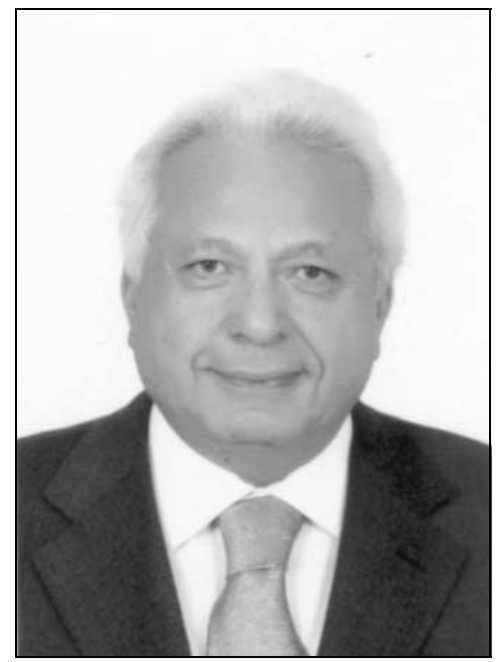

of Mortality and Disability from Diseases, Injuries, and Risk Factors in 1990 and Projected to 2020 (Murray \& Lopez, 1996); transcultural research studies, especially in obsessive-compulsive disorder.

\section{What is the most promising} opportunity facing the profession? Bridging the gap between the hardware (neurology) and the software (psychiatry)

What is the greatest threat? Attempts to demedicalise psychiatry.

\section{What single change would} substantially improve quality of care? Reducing stigma and discrimination because of mental disorder. Parity in budget and resources with other medical diseases especially since disability-adjusted life years (DALYS) is more important for psychiatry than any other medical specialty. Increased awareness that the pain of psychiatric patients exceeds the pain associated with other medical illnesses.

\section{What conflict of interest do you} encounter most often?

Scientific activities that are sponsored by industry may be biased. Good clinical and humane practice $v$. the interests of thirdparty sponsors

Do you think psychiatry is brainless or mindless?

Psychiatry is a neuro-clinical science based on brain circuits affected by psychosocial factors. Brainless and mindless is the language of the past century.

How would you entice more medical students into the profession? By having more charismatic, integrated teachers of psychiatry reaching every student. Most medical students specialise following identification with teachers.

What is the most important advice you could offer to a new trainee?

Treat the patient as a person not as an organ. Psychiatry is the most humane of medical specialties. Disability caused by mental disorder exceeds that associated with other medical disorders.

What are the main ethical problems that psychiatrists will face in the future?

The ethics of implementing new technology in psychiatry, for example genetic engineering. etc.; the ethics of disclosure of information when violence is a major part of our current culture. The ethics of minimising services at the expense of maximising profit for medical insurance corporations.

How would you improve clinical psychiatric training?

By having an emphasis on medicine and neurology as in the past. If we reinstate training in medicine this will improve clinical psychiatric training and the image of psychiatry. We should focus on what psychiatrists can do that others cannot do.

What single change to mental health legislation would you like to see? Legislation for the treatment of addicts to address their negative impact on families and societies. Open-minded legislation for personality disorders.

How should the role of national bodies such as the Royal College of Psychiatrists and the American Psychiatric Association change? These should reduce their isolation from medicine and include medicine and neurology in the Membership and the Board examinations. The examinations should be geared towards good clinical psychiatrists rather than psychologists, psychiatric social workers or philosophers.

What is the future for psychotherapy in psychiatry training and practice? You cannot practise any branch of medicine and specifically psychiatry without being able to listen. There will always be a future for psychotherapy. The great Islamic physician, of the 11th century, El Razy, in his famous textbook El Hawy mentioned that medicine is the art of 'Al mowassah' (listening, sympathy and positive regard) followed by medication (Al Modawah).

\section{What single area of psychiatric} research should be given priority? Addressing the management of subsyndromal disorders, especially since the recent literature shows equal disability to that of syndromal disorders.

What single area of psychiatric practice is most in need of development? We need to develop more emphasis on training in clinical phenomenology than detecting criteria from ICD-10 or DSM - IV, which is unfortunately the main goal of the trainee for their examinations.

Dominic Fannon and Lucy Watkin 